\title{
FAMILY STRUCTURE AND PEER GROUP AS RISK FACTORS TO SUICIDAL BEHAVIOUR AMONG THE YOUTHS IN EKITI STATE, NIGERIA
}

\author{
* Rufus Ajayi Alonge (PhD) \& ** Bilqees Olayinka Abdu-Raheem (PhD) \\ Department of Social Science Education, Faculty of Education, \\ Ekiti State University, Ado-Ekiti, Nigeria.
}

\begin{abstract}
This study investigated family structure and peer group as risk factors to suicidal behaviour among the youths in Ekiti State, Nigeria. The study adopted descriptive research design of the exploratory type. The population for the study comprised all youths in Ekiti State, while the sample consisted of 300 male and female youths and young adults within the ages of 13-55years. Stratified random sampling technique was used to select the sample to accommodate family structure and gender strata from two out of the three Senatorial Districts (Central and South) in Ekiti State. Fifty youths were selected from each of the three Local Government Areas in each Senatorial District making a total of six Local Government Areas and two Senatorial Districts arriving at 300 youths altogether. The instrument for the study was questionnaire to collect data on risk factors to suicidal behaviour among youths in Ekiti State. The validity of the instrument was considered through face and content validity procedures. The reliability was considered using Cronbach alpha and the coefficient yielded 0.79. Two research hypotheses were generated and tested at 0.05 level of significance. The data collected were analysed using frequency count, mean, standard deviation and Pearson Product Moment Correlation statistical tools. The study found that there was significant relationship between family structure as well as peer group and youth suicidal behaviours in Ekiti State. It was concluded that family disruption and bad peer group contribute to youth suicidal behaviours in Ekiti state. It was therefore recommended that couples should avoid all acts of omission and commission that could lead to disharmony among them, and also be watchful of the type of friends their children keep.
\end{abstract}

KEYWORDS: family structure, peer group, suicidal behaviour, tragedy, risk factors.

\section{INTRODUCTION}

Suicide is an enormous social-health problem in Nigeria and around the world as it affects both the direct sufferer and other people who are either directly or indirectly connected to the direct sufferer. The word suicide originated from the Latin word ...Sui (of oneself) and ...caedes (killing). This was first introduced by a Philosopher called Sir Thomas Browne in the 17th century. Suicide is the intentional taking of one's own life using any dastardly acts (Samm, 2012). Suicide, according to Okoedion and Okolie (2019), is a fatal self-inflicted act with the explicit or inferred with the intension to die. Corroborating this, Ogunleye, Azikiwe, Aroso, Tenibiaje and Solomon (2019) posited that suicide is a complex behavioural phenomenon that involves the act of taking one's life by oneself. 
According to Mba (2010), suicidal behaviour is any deliberate action that has life threatening consequences such as drug abuse and conscious/deliberate over-speeding that could lead to car crashing. Such threatening tendencies are common among the contemporary youths, which some people believed to be an act of youthful exuberance. Suicidal behaviour can be described as a set of non-continuous and heterogeneous spectra of behaviours which includes suicidal ideation, suicidal threats, gestures, self-cutting, low lethal suicide attempts or actual suicide and many others not so related (Samm, 2012). It was further stated by Sam (2012) as any deliberate action and inaction intended to end one's own life in other to escape unbearable suffering or to help change adverse conditions of living. The Yoruba has an adage that supports this assertion: 'Iku ya j'esin', meaning 'death is better or preferred to ignominy'. People who believed in this assertion that 'death is preferred to ignominy' engaged in suicide with the mission to end it all and save their faces as that could probably put an end to the problems they were facing or the reproach in their lives. Suicidal behaviour is the domain of thoughts, images and ideas about committing suicide or desire to terminate one's life without the suicidal act (Okoedion \& Okolie, 2019).

Suicidal behaviour has been categorised into various classifications. For instance, Robert cited in Samm (2012) put the four categories of suicide as: suicide ideation, suicide attempt, selfdestructive acts and completed suicide. Eze, Chukwuorji, Ettu, Zacchaeus, Lorfa, and Nwonyi (2019) posited that suicide ideation has to do with all overt suicidal behaviours and communications that depict that this one is contemplating to die like issuing suicide threats and making it a constant expression to who care to listen. Oginyi, Mbam, Sampson, Chukwudi and Nwoba (2018) posited that suicide ideation is a serious psychological social and cultural, public health problem which is a source of great concern to people all over the world. By suicide attempt, the person involved has taken a step further from issuing threats to actually carrying out the threats but he actually survives it; peradventure he took overdose drug and before serious damage is done, he has been rescued. Self-destructive acts are behaviours that kill gradually. A good example is the slogan written on every stick of cigarette in Nigeria that 'Smokers are liable to die young' (Federal Ministry of Health, 2020). Completed suicide is a behaviour that resulted into the death of the victim.

According to Kerkoff, as reported by Mba (2010), that suicidal behaviour involves not only the pain, but also the individual's willingness to tolerate that pain, the decision not to endure it and the active will to stop it. Many youths of modern day Nigeria, and with particular reference to Ekiti State, are faced with suicidal behaviours and other self-destructive acts that do not lead to immediate death but kill gradually but after while will ultimately lead to death. Many youth seem to engage more in alcoholism, sexual immorality, drug abuse, cultism, reckless driving, armed robbery and possession of lethal weapons. Youth engagement or involvement in the above acts and practices could have been a response to situation(s) that they considered as too overwhelming (Wanyoike, 2015). However, overbearing anxiety, ungodly mood, social isolation, and substance abuse disorder, death of close relation, emotional trauma and serious or terminal ailment could have resulted in putting up such acts. 
The term 'Suicidal behaviour', according to Animasahun and Animasahun (2016) is the complex and multi-factorial events with different behavioural characteristics incorporating a range of selfharming acts precipitated by emotional discomfort and distress. Youths are very important all over the world and this has made the World Health Organisation (WHO, 2017) recognised that investing in the youths and young adult offers triple dividends through the immediate outcome during the adolescent period in their adult life and well-being of their future children. WHO (2018) posited that people of all ages commit suicide and suicide is a tragedy that affects families, communities and the country as whole leaving behind long-lasting sorrowful effects. Decker, Wilcox, Holliday and Webster (2018) also agreed that suicide is a global health problem and a leading cause of mortality for all age groups. Cha, Franz Guzman, Glenn, Kleiman and Nock (2018) lamented that rise in suicide death among youth especially between adolescent to young adulthood compared to other age groups was a source of serious concern that needed urgent attention.

Youth comprised the largest population of every society of the world, and Nigeria, nicknamed the 'Giant of Africa' is one of the countries that have the largest number of youths in the world. Youth are young, strong and energetic set of people in a country. Youth percentage of Nigeria's huge and increasing population consists of an estimated 31.6 per cent (National Population Commission, \& ICF International, 2013). The current estimated number of youths in Nigeria is 33,652,424 (Youth in Nigeria: Wikipedia) out of the total population of $206,139,589$ million people ranking $7^{\text {th }}$ in the world as at 2020 (Nigeria Population 2020: Worldometer). It is worrisome and unfortunate that suicide mostly occurs among youths and young adults between the ages of 15-19 years old (WHO, 2013).

Until recently in Nigeria, there have been several reports of adults jumping into the Lagos Lagoon and others hanging themselves, but the trends seem to have dramatically shifted in the last few years as more teenagers, youths and young adults are now taking their lives or ending it all, with the act of poisoning themselves using insecticides and other destructive chemicals that kill quickly. Statistically, over 800,000 people commit suicide globally per annum (WHO, 2016). It was further reported by World Health Organisation Suicide Prevention Programme (SUPRE) that over one million people commit suicide annually (WHO, 2016).

\section{Some Recent Cases of Suicide in Nigeria}

Punch Newspaper in 2017 reported that an undergraduate of a private university in Nigeria, aged 19 years committed suicide in his parent's house at Oshodi, Lagos. Another 500 level undergraduate of Ladoke Akintola University of Technology (LAUTECH), Ogbomosho was reported to have also committed suicide by hanging himself in his hostel room. Again, The Guardian Newspaper of 12th June, 2018 reported that 80 persons mostly youths committed suicide in a year (Ogunleye, Aroso, Tenibiaje, \& Solomon, 2019). The Guardian Newspaper of 21st May, 2019 reported that Temitope Saka a 17-year old girl decided to end it all by drinking sniper poison because she had unwanted pregnancy and because of this incident her grandmother maltreated her which led her to committing suicide. The Guardian Newspaper (21st May, 2019) also gave the 
account of 19-year old Uche Obiora and Akachi Chukwue a 400 level student of the Department of English and Literary Studies of the University of Nigeria, Nsukka who took their lives. Obiora was reported to have engaged in unholy relationship that made her to take poison in her boyfriend's house but Akachi reportedly took poison because he failed to graduate with his mates at the right time.

In addition, Loveth, a 17-year old girl who scored 163 marks in 2019 UTME and she believed that she might not be admitted that year took three bottles of snipers to end it all (Premium Times, 2019). The Nation Newspaper, May 18, 2020 also reported that a 13-year old girl has reportedly committed suicide in Warri, Delta State over the beaten she received from her sister for engaging in sexual affairs. She took an insecticide and ended up behind a Total Filling Station near Warri Main Garage in the oil-rich city. The Guardian Newspaper of May 21, 2020 reported that a man identified as Kelvin Rhima committed suicide at Modinatu Street in Ogba area of Lagos State. He was working with a new generation Bank and lost his job. He reportedly hanged himself in his one-room apartment and dropped a suicide note for his father and girlfriend. Emily Emmanuel reportedly twisted a suicidal note for his mother on May 20, 2020 because of lack of job to cater for himself. All efforts from Twitter users to reach him proved abortive. Another 50-year-old man identified as Chukwudi Maduka reportedly committed suicide on Tuesday, May 19, 2020 at Umuazu-Ore Umuana village in Uhuahia North Local Government of Abia state. The deceased set his apartment on fire before hanging himself (The Guardian Newspaper 21st May, 2020).

Similar cases of youth suicide had been reported in Ekiti State, Nigeria. Roundup Newspaper (2019) reported that on the 26th October, 2019, Opeyemi Oluwafemi a 17-year old boy from EpeEkiti in Ijero Local Government Area of the state committed suicide. He reportedly hanged himself in the bush not too far from the town. It was believed that the young man might have been compelled to end it all over alleged maltreatment melted on him by his own father at the slightest provocation. On June 8, 2019, a final year student of Ekiti State University Ado-Ekiti, Akindeko reportedly attempted suicide over poor academic performance (Premium Times, 2019). On October 29, 2019, a 17-year old boy reportedly committed suicide in Ado-Ekiti (Daily Trust, 2019). Afolayan Tope, a civil servant in the state reportedly hanged himself over unpaid salaries and huge burden of indebtedness. The case of a Local Government Director of Finance in Ekiti State, who jumped into a well in his own house without leaving any suicide note to ascertain the reason behind the act was also reported (Roundup Newspaper, 2019). All these cases suggest that all is not well with Nigerians both old and young ones. People are desperate to end it all not minding the consequences of such action on self, the family and the society.

In Ekiti State, like any other states in the country, there are many factors that could lead people to commit suicide. Suicide which is the act of killing oneself may be as a result of family issues, family suicidal history, socio-economic status of parents, anxiety, depression, serious physical illness, psychological, social, spiritual or emotional problems, unemployment/loss of jobs, disappointment from opposite gender, lack of moral/religious values, death of parents or loved 
ones, loneliness, peer influence, drug abuse, maltreatment and financial problem. Oginyi, Mbam, Sampson, Chukwudi and Nwoba (2018) posited that suicide is the most worrisome psychological problem that significantly increases or leads to death among university undergraduates in Nigeria, who are mostly youths. Suicidal behaviour in any person whether young or old implies that something is somewhere wrong with the fellow or with the environment in which the individual exist and it could be both.

The study of Durkheim (1897/2010) emphasised the concept of suicide through the social structure and its relationship to how individual members of the societies is a dimension of social integration reflecting the degree to which members of the society are bound together through the family institution and the social regulation that marks the strength of the society's norms, rules and values. This therefore posits that too weak or too strong social integration coupled with regulation or lack of regulation of the individual by the society generates suicide. The position of Durkheim generated lot of criticisms. Notwithstanding, his work was seen as the first to investigate suicide as a social issue and presented it as a social problem, bearing in mind the place of social regulation and family institution. In line with Durkheim's position and using it as a foundation for this study, the researchers looked at the risk factors to suicidal behaviours as related to family structure and peer group.

\section{Family Structure and Youth Suicidal Behaviours}

Family, as the smallest unit of social institutions has major roles to play in the life of the youth. Failure of the family to provide psychological, social, economic and emotional supports for the youth can lead to suicidal behaviour and suicide attempt. One of the most important sources of support which address the many challenges of youth is the family context in which young people live or have grown up. According to Brert and Man (2006) suicide behaviour has been linked to several risk factors of which family structure is a pointer. Animasahun and Animasahun (2016) opined that family and friends can be major risk factors to suicidal behaviour of the youth as a result of interpersonal relationships that exist between them. The researchers stressed further that parental divorce, death of parents, interpersonal conflicts between parents and siblings, preexisting family psychiatric conditions and suicidal behaviours in the family context can all lead to sense of insecurity and risk of suicidal behaviour. Parental divorce is associated with suicide of the youth involved, and this closely associated with the practical financial and socio-economic implication of living in a single-parent family (Im, Ow and Suk, 2017).

In addition, violence at home front, which creates unhappiness, irrational thinking, lack of peace and real love, communication gaps, disunity and family disruptions, is noted to be found in the background history of youth suicide cases. Kim, Park and Yoo (2015) discovered that perceived level of household income and education are significantly related to suicidal ideation and behaviour. Moreover, Hamilton and Scumpasa-Kenyinga (2016) noted that socio-economic status and parental educational level are highly related to suicide ideation and suicide attempt. In their own contributions, Animasahun and Animasahun (2016) emphasised that secure and stable 
relationships with family and peers not only assist adolescents to have smooth transition to adulthood, but also assist them to cope with life problems, therefore safe guard them from suicidal behaviours. Adeleke (2017) also observed that life frustration such as failure, marital separation and loss of loved ones could bring about extremely serious pressure on one's life and can lead to suicidal behaviour.

Closely related with the above is the issue of effective and robust communication among members of the family. King and Merchant cited in Samm, Tooding, Sisask, Kolves, Aasvel, and Vairnik (2010) argued that young peoples' suicide behaviours and adults that died by suicide had significant less frequent and satisfying communication with their parents with no evidence of more negative interactions with the mothers and fathers. Poor communication within the family or about the child's problems could be a risk factor to suicidal behaviours among the youths. Samm (2012) posited that good communication between husband and wife and their children is capable of reducing the risk of suicidal behaviours and ideation among the youth whether male or female. Direct conflicts between parents and with parents have significant impact on youth suicidal behaviours and so do the absence of communication and neglect of communication need. Mckinnon, Gariepy, Sentenac and Elgar (2016) also found that physical violence, loneliness, bullying, maltreatment or inadequate parental supports are risk factors associated with youth suicidal behaviours. Suicide ideation and attempt of the youth could be as a result of lack of communication between couples and their children. Many people seem to be in the habit of bottling up so many grievances for days/months and once they explode, the aftermath is always very catastrophic on the couple and their children.

While contributing to the implication of family structure to youth suicidal behaviours and ideation, Adewuya and Oladapo (2019) indicated in their study that family-related variables such as age, type of family (monogamy and polygamy), number of siblings (family size), position of the adolescent among the siblings, socio-economic status of the family, parents drinking and smoking habits, occurrence of domestic violence/maltreatment of adolescents are all highly connected with youth suicidal behaviours and ideation. They found that adolescents from divorced parents, parents with smoking habit, low socio-economic status, older age, extreme level of corporal punishment/child abuse as an appropriate method of discipline nearly double the likelihood of suicidal behaviours and attempt. All these put together are reflections of the family structure on the suicidal ideations and behaviours among the youths and such do have grave consequences on the youth's lives.

\section{Peer Group and Youth Suicidal Behaviours}

Peer group is a group of people who are approximately the same age and status, especially if they have the same interest and share the same mind on certain issues. Despite the great value of the youth in the society, they are faced with lots of challenges especially during transition from adolescence to adulthood. In some cases, the challenges are of various dimensions and degrees as it ranges from health problems, loneliness, and parental issue to cases of depression which may 
eventually result to suicidal behaviours. According to Nyundo, Manu, Regar, Ismail, Chukwu, Dessie, Njau, Kaaya and Fawzi (2020), adolescents are confronted with various psychosocial challenges due to lack of information on their growth and development and limited societal understanding of adolescence. They stressed further that life challenges may contribute to psychological stress, anxiety and depressive disorder that could result in engagement in suicidal ideation and suicidal behaviours.

Peer provides youth with important opportunities to discuss feelings, expend thought processes and knowledge, experiment with language and social roles. Peer group has the privilege of giving members the opportunity to choose to embark on something they would not otherwise do, because they wanted to feel accepted and valued by their acquaintances. Various factors have been adduced to be associated with suicidal behaviours among the contemporary youths in Nigeria. These factors include depression, alcoholism, substance abuse, possession of lethal weapons, terminal illness, disappointment in relationship, loss of loved ones, crashing of a booming business among others. For instance, many youths take to alcoholism as a result of peer influence to wipe off depression and get rid of disappointment in relationship.

The growth in youth and young adult suicide ideation and behaviours seem to be in the increase compared to the youth of the $19^{\text {th }}$ century. This could be attributed to the fact that the young adults in recent times often spend substantial amounts of time and energy in social media/worlds quite distant from the adults who have putative moral authority over his or her behaviour. Corroborating this, the Guardian (2019) reported that, there are peculiarities of young adults who fall within the age bracket of 13-35 who were born in between 1980-2014. It was further reported that this group of young adults are less traditionally attached to the extended family stuff and are more likely to be given birth to by single parents who are often entrepreneurs and the children are more into phone chatting and addictive television viewers where they come across or exposed to media bullying and other scenes/channels that promote suicidal ideation and behaviours. It was observed that this group of young adults are more likely to have less social and interpersonal skills compared to the older generations and many of such youths are engrossed with fake personality and living a 'make believe lives.'

Furthermore, Obinna and Olawale (2019) as reported in the Vanguard Newspaper of 21st May, 2019 that Nigeria as a country may witness more suicidal behaviours and complete suicide among the youths. According to them, the country is busy breeding immature adults who depend on peer group to act and take decisions. The new generations of youths are quite disconnected with the traditional bond and ties that once existed between families which has now disappeared and the society is increasingly more frivolous. The extinction of the traditional bond of family structure and the desperation of the youth to make it at all cost not minding the consequences are some of the causes of the root cause of suicidal ideation and behaviours among the youths in Nigeria. 
The study of Samm (2012) revealed that youths who were exposed to early sexual debut are of high risk for suicidal ideation and behaviours. It becomes higher in the young adults that were early exposed to sexual intercourse experiences when compared with late sexual intercourse debut. The younger they lost their virginity, the more frequently they use substances believed to be useful for pregnancy prevention purpose, the more aggressive they are, and the more they are exposed to cases that promote suicidal behaviours like engaging in abortions. Samm (2012) affirmed that there is greater frequency of risk behaviours within the peer groups as they are found of taking up lots of challenges.A lot of researches have been conducted on suicide, suicidal ideation and behaviours, prevalence and preventions in Nigeria but studies on the risks factors precipitating suicidal behaviours among the youths in Ekiti State, Nigeria represents the tip of the iceberg. It is expected that more researches in this area would yield further insights into the researchers' knowledge base and serves as the crux of knowledge about suicidal behaviours and the risk factors in the State and the country as a whole. It is therefore against this backdrop that this study explored family structure and peer group as risk factors to suicidal behaviour among the youths in Ekiti State, Nigeria.

\section{Statement of the Problem}

It has been observed that a good number of contemporary youths in Nigeria and in Ekiti State in particular are suffering in silence and faced with lots of excruciating challenges that damper their self-esteem and lead to depression when in the real sense of it, the parents and governments fail to provide for the needs of the youths and inability to accomplish such needs may constitute depression and suicidal ideation/behaviours. A good number of factors ranging from psychological factors, economic factors, environmental factors, corporal punishment, physical and mental health problems, drug addiction, unemployment /loss of jobs, family issue and history, among others have been observed as part of factors associated with significant increase in suicidal behaviours among youths. The researchers noted that parents, foster parents, governments and other stakeholders appear not to be conscious that today's youths need more attention than before because of lots of challenges and risks they are exposed to that promote suicidal behaviours in the current dispensation. However, the researchers are interested in finding out how family structure and peer group, as risk factors contribute to suicidal behaviours among the youths in Ekiti State.

\section{Purpose of the Study}

The purpose of the study was to determine the relationship between family structure as well as peer group and youth suicidal behaviour among youth in Ekiti State, Nigeria. The study aimed at proffering necessary solutions through recommendations to contain the menace in Ekiti State and Nigeria in general. 
Vol.8, Issue 6, pp.33-47, June 2020

Published by ECRTD- $U K$

Print ISSN: ISSN 2054-6351: Online ISSN: ISSN 2054-636X

\section{Research Hypotheses}

The following research hypotheses were generated and tested in this study:

1. There is no significant relationship between family structure and suicidal behaviour among the youths in Ekiti State.

2. There is no significant relationship between peer group and suicidal behaviour among the youths in Ekiti State.

\section{METHODOLOGY}

The design used for this study was the descriptive research design of the exploratory type where copies of questionnaire were given out to the respondents who are youths within the ages of 1355 years. This is done to be able to sieve out those who are not within the age brackets and to provide the researchers the opportunity to utilise quantitative approach in collecting and analysing data collected for the purpose of the study. The population comprised all youth both female and male in Ekiti State, Nigeria. The sample consisted of 300 youths selected through stratified random sampling technique to accommodate family structure and peer group strata from two Senatorial Districts (Central and South) out of the three Senatorial Districts in Ekiti State. Fifty youths were selected from each of the three Local Governments in each Senatorial District making a total of six Local Government areas and two Senatorial Districts arriving at 300 youths altogether. The instrument used to collect data was a questionnaire whose validity was assured through face and content validity procedures.

The questionnaire was divided into two sections. Section A was designed to get information on youths' bio-data; Section B contained 20 behavioural statements for the respondents to ascertain their level of involvement in suicidal ideation and behaviours. The reliability was established using Cronbach-alpha and the reliability coefficient of 0.79 was obtained. The instrument was first administered on 20 youths outside the six Local Government areas sampled for the study. The instrument was personally administered by the researchers and some research assistants at various Local Government areas aimed at obtaining uniform instruction on the questionnaire. Data collected were analysed using Frequency Count, Mean, Standard Deviation and Pearson Product Moment Correlation statistical analysis. All the hypotheses were tested at 0.05 level of significance. 
Vol.8, Issue 6, pp.33-47, June 2020

Published by ECRTD- $U K$

Print ISSN: ISSN 2054-6351: Online ISSN: ISSN 2054-636X

\section{RESULTS}

Testing of Research Hypotheses

Research hypothesis 1: There is no significant relationship between family structure and suicidal behaviour among the youth in Ekiti State.

Table 1: Pearson Correlation of Family Structure and Youth Suicidal Behaviours.

\begin{tabular}{lccccccc}
\hline Variable & N & Mean & SD & df & r-cal & r- tab & Remark \\
\hline Family Structure & 300 & 16.06 & 1.06 & 298 & $0.452^{*}$ & 0.195 & Sig. \\
Youth Suicidal Behaviours & 300 & 11.50 & 1.14 & & & &
\end{tabular}

$\mathrm{P}<0.05$

The above revealed that $r-c a l(0.452)>r-t a b(0.195)$. The null hypothesis is thereby not accepted. This implies that there was a significant relationship between family structure and youth suicidal behaviours in Ekiti State.

Research hypothesis 2: There is no significant relationship between peer group and suicidal behaviour among the youth in Ekiti State.

Table 2: Pearson Correlation of Peer Group and Youth Suicidal Behaviours.

\begin{tabular}{lccccccc}
\hline Variable & N & Mean & SD & df & r-cal & r- tab & Remark \\
\hline Peer Group & 300 & 13.57 & 1.19 & & & & \\
Youth Suicidal Behaviours & 300 & 11.13 & 1.04 & & & & \\
\hline
\end{tabular}

$\mathrm{P}<0.05$

Table 2 showed that the $r-c a l(0.458)$ is greater than the $r-t a b(0.195)$. The null hypothesis is thus not accepted. There was therefore a significant relationship between the peer group and youth suicidal behaviours in Ekiti State.

\section{DISCUSSION}

In this study, the researchers examined family structure and peer group as risk factors to suicidal behaviour among the youth in Ekiti State. Findings from this study indicated that there was a high positive relationship between family structure and youth suicidal behaviour. This study supported Mckinnon et al (2016) who found out that maltreatment or inadequate parental supports are part of the risk factors associated with youth suicidal behaviours emanating from family structure. For instance, where the parents are divorced or a large family size, maltreatment and inadequate support from the parents cannot be over-emphasised or ruled out. In another perspective, the study 
corroborated the findings of Animasahun and Animasahun (2016) which claimed that the family structure with all its issues are pointers to youth suicidal behaviours. Sabari and Shashikiran (2016) reported that an average of 269 suicides takes place every day and family problems and illness are the main causes of suicide in India. This was further affirmed by the work of Adewuya and Oladapo (2019) which claimed that family related variables are highly connected with youth suicidal behaviours, because when it is well with the family members, the youth is not an exemption.

In addition, it was discovered that there was a relative high correlation between peer group and suicidal behaviour. The finding corroborated the observation made by Obinna and Olawale (2019) which posited that peer group has great influences on young adults as regards the actions and decisions taken by them because according to the duo, the contemporary youths are immature as their actions and decisions are based on peer's influence. A good example of this is their early exposure to sexual debut. Samm (2012) reported that one of the factors related to youth suicidal behaviours based on peer group was their introduction and exposure to early sexual debut with the high risk to suicidal behaviours. The reason given for this was that, such youth would also be frequent in the usage of pregnancy preventive substances and abortion drugs which are indirectly related to engaging in suicidal behaviours. One hypothetical example to this was the case of a 17 years old girl-Temitope Saka as reported by the Guardian Newspaper of $21^{\text {st }}$ May, 2019, who took bottles of snipers poisons because she was scolded for engaging in illicit sexual relation that led to unwanted pregnancy. That singular act reportedly led to her demise.

Many contemporary youths engaged in actions that depict suicidal behaviours and this could be attributed to the increase in the number of youths that engaged in suicidal behaviour when compared with the adults. In comparing the incidence of youth suicidal behaviour with adult suicidal behaviour, Nock, Borges, Bromet, Cha, Kessier and Lee (2008) posited that the youths are more prone to suicidal behaviours than the adults. The reason adduced for this among others is that, the contemporary youths engaged more in behaviours that promote suicide. It was further stated that the lifetime prevalence of each individual's suicidal behaviour among adults is lower than the 12-month prevalence among young adults in the United States of America (Nock, Borges, Bromet, Cha, Kessier and Lee, 2008). This implies that, young adulthood and youth are the times of greater risk for onset of suicidal behaviours.

\section{Implications of the Study}

Family structure and peer group are risk factors to suicidal behaviour among the youths in Ekiti State, Nigeria have added to the existing knowledge-base in a number of ways in upholding the sanctity of life. The findings from this study showed that a great significant relationship exist between family structure and youths suicidal behaviour. The implication of this study is that the wellness of the family institution is germane in checking the menace of youth suicidal ideation and behaviour because sanctity of life is further attainable when all is well with every member of the family institution especially the young adults. 
The finding from this study also showed that there is a significant relationship between peer group and suicidal behaviour among the youths in Ekiti State, Nigeria. The implication of this to sanctity of life for the youths is that it required parents to be more concerned about the welfare of their children and also be more familiar with the kind of friends their children keep. This would definitely assist them to discover early any noticeable changes in the behaviours of their children that could result in committing suicide and be quick to avert it.

\section{CONCLUSION AND RECOMMENDATIONS}

Based on the findings of the study, it can be concluded that family structure and peer group are critical risk factors of youth suicidal behaviours. Based on the findings, the following recommendations were made:

1. Family harmonious relationships, that depict effective communication among members of the family, should be given priority to avoid risks of suicidal behaviours that could damage the future of their children.

2. Parents should emphasise and encourage healthy peer relationship among youths aimed at promoting healthy living rather than promoting risk factors that aid suicidal behaviours.

3. Couples should avoid all acts of omission and commission that could cause divorce or family disruption which could lead their children to life frustration and eventually terminate their lives through suicide.

4. Parents should limit their numbers of children, so as to be able to cater for them through provision of essential needs. This could enable the children to be happy always and be distanced from negative thinking such as suicide.

5. Parents should give moral and spiritual value education to their children from beginning of their lives. This could assist them to have fear of God and keep away from bad gangs that could lead them astray to commit suicide.

6. Parents should join hands together to train children on how to lead their lives, manage stress or proffer positive solutions to issues that come their ways. This could assist the children to be emotionally stable and psychologically balanced in life.

7. Government should provide a state-based research platform where causes of suicide especially among the youth would be addressed and suicidal ideation/behaviours be prevented to assist the youths fulfill their God given visions and aspirations.

\section{REFERENCES}

Adeleke, C. (2017). Life frustration and emotional behaviour among Nigerian University students: Affiliation or commitment? African Journal of Reproductive Health, 9, 125-140.

Adewuya, A. O., \& Oladapo, E. O. (2019). Prevalence and associated factors for suicidal behaviours (ideation, planning and attempt) among high school adolescents in Lagos, 
Nigeria. European Child and Adolescent Psychiatry. Retrieved from https//doi.org/101007/s00787-019-01462-x on April 15, 2020.

Animasahun, R. A., \& Animasahun, V. O. (2016). Psychosocial predictors of suicide mission among Nigerian youths. African Journal for the Psychological Study of Social Issues, 19(1), 79-102.

Brent, D., \& Mann, J. (2006). Familiar factors in adolescents suicidal behaviours. In R. King, and A. Apter (Eds), Suicide in children and adolescents. Cambridge: Cambridge University Press. 86-117. Goggle Scholar, Retrieved 21st April, 2020.

Cha, C. B., Franz, P. J., Guzman, E. M., Glenn, C. R., Kleiman, E. M., \& Nock, M. K. (2018). Annual research review: Suicide among youth-epidemiology (potential), etiology, and treatment. The Journal of Child Psychology and Psychiatry, 59(4), 460-482. https://doi.org/10.1111/jepp.12831. Retrieved 21st April, 2020.

Daily Trust-https://www.dailytrust.com.ng>.... retrieved April 15, 2020.

Decker, M. R., Wilcox, H. C., Holliday, C. N., \& Webster, D. W. (2018). An integrated public health approach to interpersonal violence and suicide prevention and response. Public Health Reports, 133(1), 65S-79S. https://doi.org/10.1177/0033354918800019.

Durkheim, E. (1897/2010). Suicide: A study in sociology. London: Routledge Classic.

Eze, J. E., Chukwuorji, J. C., Ettu, P. C., Zacchaeus, E. A., Lorfa, S. K., \& Nwonyi, S. K. (2019). Bullying and suicide ideation: Testing the buffering hypothesis of social support in a subSahara African sample. Journal of Child and Adolescent Trauma. https//doi.org/101007/s40653-019=00294-w

Hamilton, H. A., \& Sampasa-Kanyinga, H. (2016). Does socio-economic status moderate the relationships between school connectedness with psychological distress, suicidal ideation and attempts in adolescents? Preventive and Medicine, 87, 11-17.

Im, Y., Ow, H., \& Suk, M. (2017). Risk factors for suicide ideation among adolescents: Five years national data analysis. Aril psychiatry Nurs, 31, 282-285. Goggle scholar. Retrieved 21st April, 2020.

Kim, J., Park, E., \& Yoo, K. (2015). Effects of the gap between socio-economic status and perceived social class on suicidal ideation: Unique perspectives using a longitudinal analysis. Archives of Gerontology and Geriatrics, 61(3), 389-391. https://doi.org/10.1016/ j.archger.2015.06.002.

Mba, S. A. (2010). Prevalence and prevention of suicidal behaviours among undergraduates of universities in South Eastern of Nigeria: 1999-2008. An unpublished Ph.D. thesis, Department of Health and Physical Education, University of Nigeria, Nsukka.

Mckinnon, B., Gariepy, G., Sentenac, M., \& Elgar, F. (2016). Adolescent suicidal behaviours in 32 low and middle income countries. Bull World Health Organisation, 94-340.

National Population Commission, (NPC, Nigeria) \& ICF International (2013). Nigeria Demographic and Health Survey. Preliminary report. Abuja: National Population Commission and ICF. 
British Journal of Education

Vol.8, Issue 6, pp.33-47, June 2020

Published by ECRTD- $U K$

Print ISSN: ISSN 2054-6351: Online ISSN: ISSN 2054-636X

Nock, M. K., Borges, G., Bromet, E. J., Cha, C. B., Kessier, R. C., \& Lee, S. (2008). Suicide and suicide behaviours. Epidemiological Review of John Hopkins Bloomberg School of Public Health, 30, 133-154.

Nyundo, M., Regan, I., Dessie, C., Njau, K., \& Fawzi, M. (2020). Factors associated with depressive symptoms and suicidal ideation and behaviours amongst sub-Saharan African adolescents aged 10-19 years: Cross sectional study. Tropical Medicine and International Health, 25(1), 54-69.

Obinna, C., \& Olawale, G. (2019). More Nigerians to die by suicide if.... Vanguard Newspaper dated 21st May, 2019. Retrieved from vanguardngr.com on 22nd April, 2020.

Oginyi, C. N., Mbam, O. S., Sampson, N., Chukwudi, E. J., \& Nwoba, M. O. E. (2018). Personality factors, academic stress and socio-economic status as factors of suicidal ideation among undergraduates of Ebonyi State University. Asian Social Science, 14(9), 25-37.

Ogunleye, A. J., Azikiwe, J. C., Aroso, S. O., Tenibiaje, M. O., \& Solomon, D. I. (2019). A measure of aggression and anxiety as factors f suicide among undergraduates in a Nigerian University. Journal of Humanities and Social Science (IOSR-JHSS), 24(2), 81-87. https//www.iosrjournals.org. Retrieved 5th May, 2020 pdf.

Okoedion, E. G., \& Okolie, U. C. (2019). Youth suicidal behaviour: An evaluation of risk factors in Edo State, Nigeria. International Scientific Journal, 125, 51-71.

Punch Newspaper (2017). An undergraduate adolescent commit suicide in Lagos State. https://thepunch.com.ng

Premium Times (2019). Tuesday October 29th. https://www.premiumtimesng.com.

Roundup Newspaper (2019). https://www.roundupnews.com.ng

Sabari, N. R., \& Shashikiran, M. (2016). A cross-sectional study of suicidal attempts admitted in a rural tertiary-care hospital, Mandya, Karnataka. International Journal of Medical Science and Public Health, 5(8): 1574-1578.

Samm, A., Tooding, L. M., Sisask, M., Kolves, K., Aasvel, K., \& Vairnik, A. (2010). Suicidal thoughts and depressive feelings amongst Estonian school children: Effects of family relationship and family structure. European Child and Adolescent Psychiatry 19(5): 457468.

Samm, A. (2012). The relationship between perceived poor family communication and suicidal ideation among adolescents in Estonia. Unpublished Ph.D. dissertation, University of Tartu. University Press. Retrieved 21st April, 2020 pdf.

The Guardian (2019). Tuesday October 21st.

The Guardian (2020). Thursday October 21st.

The Nation (2020). Monday May 18th.

The Daily Trust (2019). Tuesday October 29th. https://www.dailytrust.com.ng

Wanyoike, B. W. (2015). Suicide among university students in Kenya: Causes, Implications and Interventions. Journal of Language, Technology and Entrepreneurship in Africa. 6(1), 3553.

Wikipedia (2020). Youth in Nigeria https//en.m.wikipedia.org>wiki. Retrieved 21st April, 2020. 
Vol.8, Issue 6, pp.33-47, June 2020

Published by ECRTD- $U K$

Print ISSN: ISSN 2054-6351: Online ISSN: ISSN 2054-636X

Worldometer: Nigeria Population (2020). https:www.worldmeters.info>nig. Retrieved 21st April, 2020.

World Health Organisation (WHO, 2013). Suicide prevention (SUPRE). Retrieved on April15th, $2020 \mathrm{from} \mathrm{http//www.who.int/medntal.health/prevention/suicide/suicideprevent/en/.}$

World Health Organisation (WHO, 2016). Suicide rate estimates, age-standardized estimates by country. Retrieved from https://www.apps.who.int>gho>data>view

World Health Organisation (WHO, 2017). Global accelerated action for the health of adolescents (AA-HA): Guidance to support country implementation (internet).WHO. (Available from: http//www.who.int/maternal-child-adolescent/topics/adolescence/framework-acceleratedaction/enl) (Nov. 2017).

World Health Organisation, (WHO, 2018). 800,000 people commit suicide annually. Vanguard, https://www.vanguardngr.com. Retrieved 21st April, 2020. 